\title{
Microstructural Characterization and Wear Properties of Fe-Based Amorphous-Crystalline Coating Deposited by Twin Wire Arc Spraying
}

\author{
Ana Arizmendi-Morquecho, ${ }^{1}$ Araceli Campa-Castilla, ${ }^{1}$ \\ C. Leyva-Porras, ${ }^{1}$ Josué Almicar Aguilar Martinez, ${ }^{2}$ Gregorio Vargas Gutiérrez, ${ }^{3}$ \\ Karla Judith Moreno Bello, ${ }^{4}$ and L. López López ${ }^{5}$ \\ ${ }^{1}$ Centro de Investigación en Materiales Avanzados, S.C. Unidad Monterrey, Alianza Norte 202, 66600 Apodaca, NL, Mexico \\ ${ }^{2}$ Universidad Autónoma de Nuevo León, Facultad de Ingeniería Mecánica y Eléctrica, Centro de Investigación e Innovación en \\ Ingeniería Aeronáutica, Carretera a Salinas Victoria km 2.3, 66600 Apodaca, NL, Mexico \\ ${ }^{3}$ Centro de Investigación y de Estudios Avanzados del IPN, Unidad Saltillo, Avenida Industria Metalúrgica 1062, \\ 25900 Ramos Arizpe, COAH, Mexico \\ ${ }^{4}$ Instituto Tecnológico de Celaya, A. García Cubas S/N A.P. 57, 38010 Celaya, GTO, Mexico \\ ${ }^{5}$ Corporación Mexicana de Investigación en Materiales, S.A. de C.V., Ciencia y Tecnología 790 Fracc. Saltillo 400, \\ 25260 Saltillo, COAH, Mexico
}

Correspondence should be addressed to Araceli Campa-Castilla; aracely.campa@cimav.edu.mx

Received 10 June 2014; Revised 10 September 2014; Accepted 25 September 2014; Published 20 October 2014

Academic Editor: Jörg M. K. Wiezorek

Copyright (C) 2014 Ana Arizmendi-Morquecho et al. This is an open access article distributed under the Creative Commons Attribution License, which permits unrestricted use, distribution, and reproduction in any medium, provided the original work is properly cited.

\begin{abstract}
Twin wire arc spraying (TWAS) was used to produce an amorphous crystalline Fe-based coating on AISI 1018 steel substrate using a commercial powder (140MXC) in order to improve microhardness and wear properties. The microstructures of coating were characterized by X-ray diffraction (XRD), scanning electron microscopy (SEM), and transmission electron microscopy (TEM) as well as the powder precursor. Analysis in the coating showed the formation of an amorphous matrix with boron and tungsten carbides randomly dispersed. At high amplifications were identified boron carbides at interface boron carbide/amorphous matrix by TEM. This kind of carbides growth can be attributed to partial crystallization by heterogeneous nucleation. These interfaces have not been reported in the literature by thermal spraying process. The measurements of average microhardness on amorphous matrix and boron carbides were 9.1 and $23.85 \mathrm{GPa}$, respectively. By contrast, the microhardness values of unmelted boron carbide in the amorphous phase were higher than in the substrate, approaching $2.14 \mathrm{GPa}$. The relative wear resistance of coating was 5.6 times that of substrate. These results indicate that the twin wire arc spraying is a promising technique to prepare amorphous crystalline coatings.
\end{abstract}

\section{Introduction}

Amorphous alloys are a combination of disordered structures and interatomic metallic bonding in a metastable state [1]. The amorphous structure confers exceptional properties such as high hardness, low friction coefficient, high corrosion and wear resistance, and good magnetic properties. These particular characteristics contrast with regular metallic alloys properties [2]. In spite of their good properties, the amorphous alloys have a limited plasticity due to a mechanism of heterogeneous deformation, which is identified by the formation of shear bands [3-5]. Reports in the literature [1-3] suggest the development of microstructures containing crystalline phases dispersed in the amorphous matrix, as an alternative to control the propagation of shear bands. These dispersed crystalline phases can be formed 
in situ by partial crystallization of the alloy or ex situ by the addition of reinforcement phases. A significant increase in their plasticity and fracture resistance for this type of crystalline/amorphous composite microstructures has been reported $[1-3,6]$. Previous investigations have shown great interest on the synthesis of amorphous coatings due to their outstanding properties and potential applications on corrosive and high wear environments $[7,8]$. In this sense, thermal spraying processes (TSP) are very effective for producing amorphous and thick coatings due to their rapid cooling rates of $10^{7}-10^{8} \mathrm{Ks}^{-1}$ [9]. Fe-based amorphous coatings have been one of the most extensively studied due to their unique mechanical properties, high wear resistance, excellent corrosion resistance, and low cost $[10,11]$.

Crystalline-amorphous composite coatings have been produced by thermal spraying techniques ex situ in which reinforcement phases are added and in situ through a route of a solid-solid transformation that occurs either during spraying or during a process of devitrification by a subsequent heat treatment [12]. In order to improve the mechanical properties of these amorphous coating, the use of $\mathrm{B}_{4} \mathrm{C}, \mathrm{WC}$ $\mathrm{Co}$ and $\mathrm{TiN}$ as reinforcement phases in the amorphous matrix has been reported. These coatings have been deposited by high-velocity oxygen fuel (HVOF) and gas tunnel type plasma spraying techniques [13-15]. Movahedi et al. [16] produced an amorphous feedstock powder Fe-based by mechanical alloying with high glass forming ability (GFA) and they developed amorphous-nanocrystalline coatings by adjusting spraying of HVOF parameters. However, this process presents the disadvantages of high complexity caused by the large number of processing variables during the operation, high cost of the added powders, and the formation of large agglomerates/precipitates of the dispersive phase in the coating.

In twin arc spraying process, the material precursor fed into system in the form of two cored wires and these melt within an arc electric. Compared with other thermal spraying processes, arc spraying has some advantages due to its low cost and easy application and the coatings can be synthetized successfully [17]. Nevertheless, a limited number of studies have been conducted on the development of amorphous crystalline coatings by twin wire arc spraying. In this sense Cheng et al. [17-21] deposited amorphous coatings using powders with high glass forming ability, and they reported developing of FeBSiNbCr and FeBSiNb amorphous coatings and amorphous nanocrystalline coatings FeCrBSiNbW and FeBSiCrNbMnY. On the other hand, Zhou et al. [22] sprayed Fe-based amorphous nanocrystalline coatings and found that the microstructure of the coating consisted of nanocrystalline phases embedded in the amorphous matrix. Fu et al. [23] prepared a Fe-based amorphous coating observing that the microstructure is composed of an amorphous phase with poorly distributed borides. Studies using Fe-based amorphous coatings relating the influence of the crystalline phases in the precursor powder on hardness and wear properties have not been found in literature.

The aim of the present work is to study the effect of the crystalline phases in the precursor powder on the

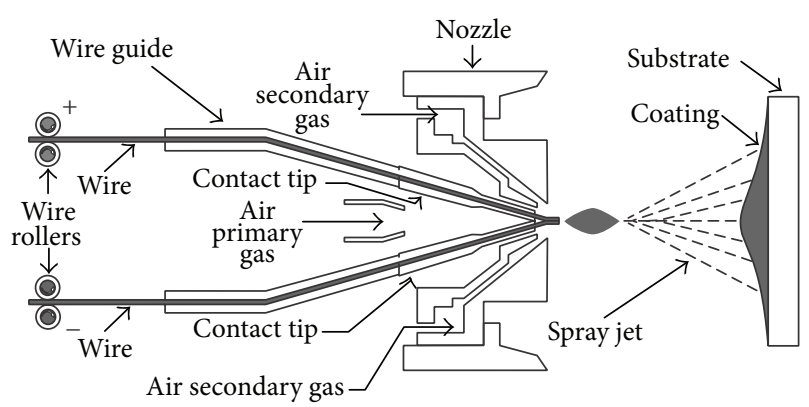

FIGURE 1: Schematic wire arc spraying process.

microstructure and mechanical properties of amorphouscrystalline composite coatings obtained by twin wire arc spraying process. The formation mechanism of crystallineamorphous coating will be discussed and it is related to mechanical and wear properties of the coatings.

\section{Materials and Methods}

2.1. Characterization of Precursor Material and Parameters of Thermal Spraying. A commercial Fe-based alloy designated as 140 MXC nanocomposite wire (from Praxair Surface Technologies) was used as precursor powder. The chemical composition was determined by combustion infrared detection for C and S in an Eltra CS 2000 equipment and by inductively coupled plasma spectroscopy (ICP) for the rest of elements in an ICAP 6200 Thermoscientific equipment.

The coating was performed in a Praxair Tafa 8835 equipment with twin-wire arc torch and an arc jet spray attachment and the wire arc spray process is shown schematically in Figure 1. An electric arc is formed in the gap between the wire tips and two wires continuously advancing melt the material. An air primary gas removes the molten particles from wire tips and an air secondary gas is used for increasing the particles velocities and these impact the substrate surface to build up the coating [24].

The coating was deposited onto AISI 1018 steel cylindrical coupons of $25.4 \mathrm{~mm}$ diameter and $6.25 \mathrm{~mm}$ in thickness. Before spraying, the coupons were degreased with acetone and grit blasted with alumina grit size 16 (particle size average $1092 \mu \mathrm{m}$ ). The used process parameters are listed in Table 1.

\subsection{Microstructural Characterization of the Precursor Powder} and Coating. Coating and precursor powder were characterized by Scanning Electron Microscope (SEM, JEOL, JSM6490LV) and High Resolution Transmission Electron Microscope (HRTEM, JEOL, JEM-2200FS + Cs). Both microscopes were equipped with an energy dispersive $\mathrm{X}$-ray detector (EDX). For TEM studies a sample of precursor powder was immersed in alcohol and ultrasonically deagglomerated to separate the particles. The suspension that contained the particles was deposited on carbon coated copper TEM grid and dried in air. Coating was prepared in cross section samples for SEM analysis with the conventional metallographic techniques and finely polished using diamond paste. HRTEM 
TABLE 1: Wire arc spraying parameters.

\begin{tabular}{lc}
\hline Parameter & Value \\
\hline Spraying voltage (V) & 32 \\
Spraying current (A) & 150 \\
Primary air pressure (MPa) & 0.42 \\
Secondary air pressure $(\mathrm{MPa})$ & 0.28 \\
Stand off-distance $(\mathrm{mm})$ & 200 \\
Number of passes & 1 \\
\hline
\end{tabular}

cross-sections were prepared using a Focused Ion Beam (FIB, JEOL, JEM-9239).

The porosity content in the coating (\% area) was estimated in SEM using image analysis with Scandium software. The porosity value was calculated by averaging 10 Backscattered Electrons (BSE) images at a magnification of 500x. The crystalline phases present in both coating and the precursor powder were characterized by X-ray diffraction (XRD) on an Empyrean analytical diffractometer equipped with a $\mathrm{Cu} \mathrm{K} \alpha$ 1 radiation $(\lambda=1.5406 \AA)$, operated at $45 \mathrm{kV}$ and $40 \mathrm{~mA}$ and using an ultra-fast X'Celerator detector with a BraggBrentano geometry. XRD scans were performed with a step size of $0.016^{\circ}$ and a dwell time per step of $40 \mathrm{~s}$ in the $2 \theta$ range of $15-130^{\circ}$.

\subsection{Mechanical Coating Characterization}

2.3.1. Microhardness. The microhardness measurements were performed in a Vickers/Knopp hardness tester Tukon $2100 \mathrm{~B}$ using a load of $3 \mathrm{~N}$ (300 gf) with a pyramidal indenter and dwell time of $15 \mathrm{~s} ; 10$ microhardness measurements were realized and the average is reported. The microhardness was measured along the plane of the cross section of coatings.

2.3.2. Wear Test. Friction and wear test was performed on pin-on-disk CSM tribometer equipped with software Tribox 4.1. Saphire ball of $6 \mathrm{~mm}$ in diameter was used as counter body and the tests were performed at normal loads of 5 and $10 \mathrm{~N}$. The sliding speed was $0.1 \mathrm{~m} / \mathrm{s}$ with a sliding distance of $1000 \mathrm{~m}$. The room temperature was measured as $25 \pm 1^{\circ} \mathrm{C}$ with relative humidity of $25-30 \%$. Before the wear test, the coatings samples were grounded with 800 emery paper and cleaned with alcohol. The worn surfaces were characterized by SEM.

Wear resistance was reported as the volume loss according to ASTM G 99-05 standard [25], considering an average of 20 measurements. The disk volume loss $(V)$ in $\mathrm{mm}^{3}$ was calculated according to (1), where $R$ is the wear track radius $(\mathrm{mm}), r$ is the sphere radius $(\mathrm{mm})$, and $D$ is the wear track $(\mathrm{mm})$, and $D$ was measured using image analysis with Image Pro-Plus software. The width of wear track was evaluated automatically with the software based on grey scale delimitation, considering an average of 10 images that were previously acquired with an Optical Microscope at 100x:

$$
V=\frac{\left(\pi R D^{3}\right)}{6 r} .
$$

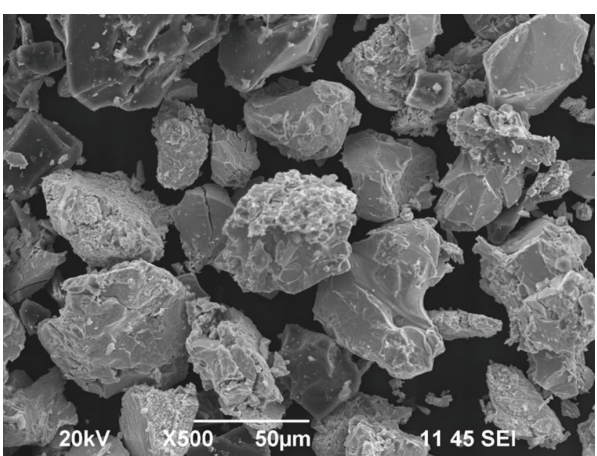

FIGURE 2: SEM image of the precursor powder particles with composition of $\mathrm{Fe}_{51} \mathrm{Cr}_{21.1} \mathrm{C}_{12.9} \mathrm{Mo}_{6.84} \mathrm{~B}_{3.21} \mathrm{~W}_{2.89} \mathrm{SiNb}_{0.47}$.

The coating wear rate in $\mathrm{mm}^{3} / \mathrm{Nm}\left(W_{\mathrm{RC}}\right)$ was calculated by using

$$
W_{\mathrm{RC}}=\frac{V}{(L S)},
$$

where $V$ is the loss volume in $\mathrm{mm}^{3}, L$ is the Load $(N)$, and $S$ the test length $(\mathrm{m})$.

\section{Results and Discussion}

3.1. Characterization of Precursor Powder. The chemical composition (wt\%) of $140 \mathrm{MXC}$ precursor powder was $20.8 \% \mathrm{Cr}$, $2.84 \% \mathrm{C}, 12.1 \% \mathrm{Mo}, 0.64 \% \mathrm{~B}, 9.79 \% \mathrm{~W}, 0.54 \% \mathrm{Si}, 0.8 \% \mathrm{Nb}$ and $\mathrm{Fe}$ as the balance. Based on this composition the calculated stoichiometric formula is $\mathrm{Fe}_{51} \mathrm{Cr}_{21.1} \mathrm{C}_{12.9} \mathrm{Mo}_{6.84} \mathrm{~B}_{3.21} \mathrm{~W}_{2.89}$ $\mathrm{SiNb}_{0.47}$.

Figure 2 depicts a SEM micrograph of precursor powder particles which present an irregular morphology type blocky as well as a nonsmooth surface. The size of powder particles is less than $100 \mu \mathrm{m}$. This morphology was previously observed on the amorphous powder consolidated by mechanical alloying as shown by Movahedi et al. [16].

Figure 3 shows the XRD pattern of the 140 MXC precursor powder. It reveals a diffuse halo centered approximately at $2 \theta=43^{\circ}$ which makes the presence of an amorphous structure evident. Likewise, several peaks were observed that correspond to crystalline phases such as chromium boron carbide $\mathrm{Cr}_{3} \mathrm{~B}_{0.4} \mathrm{C}_{1.6}$ (JCPDS File \# 01-089-25-89), boron carbide $\mathrm{B}_{13.3}$ $\mathrm{C}_{1.7}$ (JCPDS File \# 01-083-0855), niobium carbide, $\mathrm{Nb}_{6} \mathrm{C}_{5}$ (JCPDS File \# 01-077-0566), iron niobium, $\mathrm{Fe}_{6.5} \mathrm{Nb}_{6.5}$ (JCPDS File \# 01-071-8308), tungsten, W (JCPDS File \# 00-001-1203), and a Fe-Cr solid solution (JCPDS File \# 00-034-0396). It is inferred from the diffraction pattern that the precursor powder has a mixture of amorphous and crystalline phases.

The structure of crystalline phases in the powder particles was studied by TEM. Figure 4(a) shows an irregular morphology of powder particle. Figure 4(b) depicts the selected area electron diffraction (SAED) that corresponds to boron carbide phase $\mathrm{C}_{1.7} \mathrm{~B}_{13.3}$ (JCPDS File \# 98-003-4996, with space group of $\mathrm{R}-3 \mathrm{~m})$. This analysis is consistent with the XRD pattern in Figure 3. 


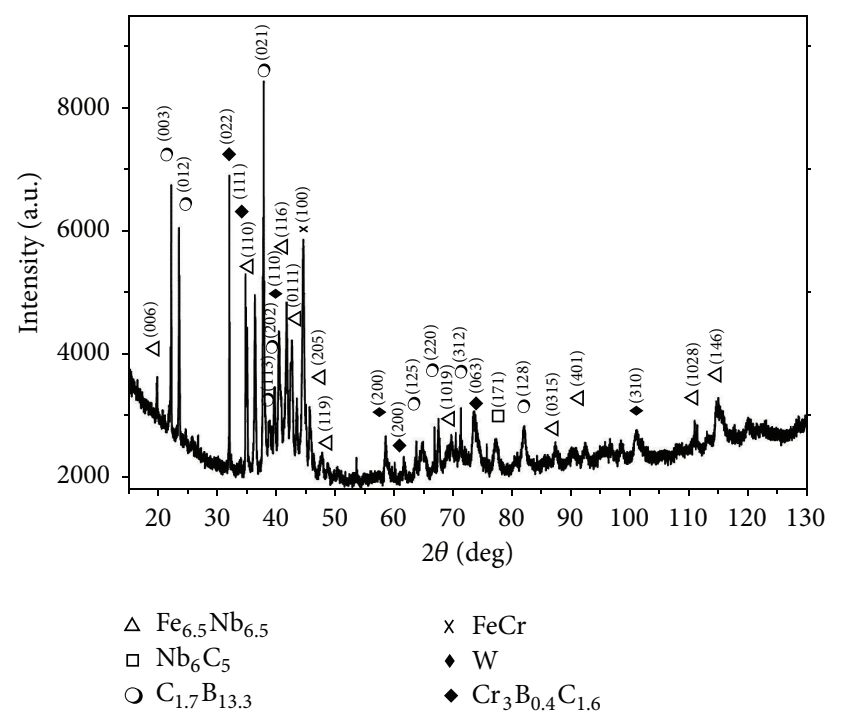

FIGURE 3: XRD pattern from the 140 MXC precursor powder.

In the case of Figures 4(c)-4(e) it can be seen powder particles of irregular morphology of polycrystalline nature. The strongest SAED diffraction rings in the pattern shown in Figure 4 (d) correspond to $\{131\}$ and $\{331\}$ niobium carbide $\mathrm{Nb}_{6} \mathrm{C}_{5}$ phase (JCPDS File \# 01-077-0566) with space group $\mathrm{C} 2 / \mathrm{m}$ and the strongest SAED diffraction rings in the pattern shown in Figure 4(f) correspond to $\{110\}$ and $\{211\}$ tungsten $\mathrm{W}$ phase (JCPDS File \# 00-001-1203) with space group I m$3 \mathrm{~m}$. These results reveal that these crystalline phases are present in powder particles of sizes smaller than $25 \mu \mathrm{m}$.

3.2. Coating Characterization. Figure 5 shows of XRD pattern of coating; it can be observed that a broad halo peak appears at $2 \theta=44^{\circ}$, which indicates the presence of an amorphous phase. Moreover, peaks due to crystalline phases are observed; these correspond to the Fe-Cr (JCPDS File \# 00-034-0396) and boron carbide $\mathrm{B}_{13.3} \mathrm{C}_{1.7}$ (JCPDS File \# 01-083-0855) phase. This result suggests that the coatings are composed by a mixture of amorphous and crystalline phases. As it can been seen in Figure 3 peaks of crystalline phases present on pattern diffraction of precursor powder disappear on the coating. These results agree with previous studies $[26,27]$ on similar Fe-based alloy deposited by HVOF, which suggest that the spray process promotes the increase of glass content on the coating compared with the precursor powder due to fast quenching of molten particles through the action of flattening on to substrate. Compared with HVOF process, the arc spray process can be considered a potential technique for synthesis of amorphous-crystalline composite coating and promotes its application.

Surface morphology of coating is observed in Figure 6(a) which is composed by individual splats with a disk like morphology shape with little splashing. This morphology indicates a good degree of deformation due to the high impact velocity of particles on the substrate. The average porosity of coating was measured by image analysis in the scanning electron microscope reaching $1.55 \% \pm 0.36$. In this sense, a
TABLE 2: Chemical analysis (EDXS) (\% atomic) on coating phases.

\begin{tabular}{lcccccc}
\hline Section & $\mathrm{Fe}$ & $\mathrm{Cr}$ & $\mathrm{W}$ & $\mathrm{Nb}$ & $\mathrm{B}$ & $\mathrm{C}$ \\
\hline $\mathrm{A}$ & 39.98 & 10.88 & 0.95 & 2.43 & 39.32 & 6.44 \\
$\mathrm{~B}$ & 0.14 & - & - & - & 99.71 & - \\
$\mathrm{C}$ & 17.67 & 5.58 & 0.36 & 3.02 & 69.43 & 3.94 \\
$\mathrm{D}$ & 0.61 & - & 24.81 & - & - & 74.58 \\
\hline
\end{tabular}

dense coating with low porosity was obtained, which affects positively the wear and corrosion resistances because of good cohesion between splats. Figure 6(b) shows the cross section image of the coating; the measured average thickness was $316 \pm 10 \mu \mathrm{m}$. SEM images from the cross sectioned coating are shown in Figures 6(c) and 6(d). As it can be seen, the coating presents a flattened lamella structure without cracks and some pores. The microstructure of the coating is mainly composed of four phases: the gray lamellae (Zone A), dark particle (Zone B), external shell with dark precipitates (Zone C), and white precipitate (Zone D) depicted in Figures 6(c) and 6(d). The dark particles and white precipitates are heterogeneously dispersed in the whole microstructure and these are magnified in Figures 6(c) and 6(d). In Figure 6(c) is shown the dark particle (Zone B), which is surrounded by crystalline phases (Zone $\mathrm{C}$ ) on the particle/matrix interface.

The elemental chemical analysis of the different phases identified in the coating was obtained by energy dispersive spectroscopy (EDXS) and the results are listed in Table 2. The corresponding zones labeled as A, B, C, and D in Table 2 are depicted in microstructures of Figures 6(c) and 6(d). Zone A is the matrix phase and it is composed by $\mathrm{Fe}, \mathrm{Cr}, \mathrm{B}, \mathrm{C}, \mathrm{Nb}$, and $\mathrm{W}$, which has similar chemical composition as the precursor powder. The elemental chemical analysis of the dark particle (Zone B) showed that boron is the main element while the same analysis for the white precipitate (Zone D) corresponds to small WC precipitated. Chemical analysis with SEM-EDXS in precipitate/matrix interface (Zone $\mathrm{C}$ ) that includes the dark precipitates embedded in the gray zone is composed by $\mathrm{Fe}, \mathrm{Cr}, \mathrm{W}, \mathrm{Nb}, \mathrm{B}$, and $\mathrm{C}$. However, the boron content was higher than in the gray phase and it can be attributed to these precipitates.

In order to get particular information from the phases in the interface boron carbide-matrix, STEM analyses were conducted. Figure 7(a) shows a STEM dark field image (Zcontrast) where the interface between the boron carbide (CB) and the matrix are observed. Boron carbide particles are observed in dark contrast, while the matrix is observed in gray contrast. In Z-contrast images, contrast is related with the square of the average atomic number. Therefore, light elements such as B and C are observed in dark, and heavy elements as $\mathrm{Fe}$ and $\mathrm{Cr}$ are observed in gray. As observed in Figure 7(a), the CB formed micrometric precipitates. These precipitates are surrounded by the different elements in the alloy. A diffraction pattern (SAED) acquired on the CB in Figure 7(c) shows the single-crystal nature of the precipitate. The indexing of the diffracting planes confirms that the precipitates were oriented very close to [211] zone axis. On the other hand, the diffraction pattern acquired from the matrix in Figure 7(b) shows the characteristics diffuse 


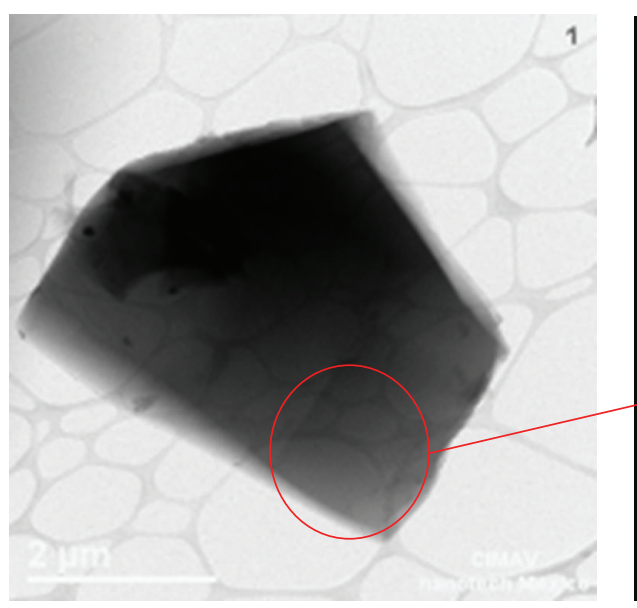

(a)

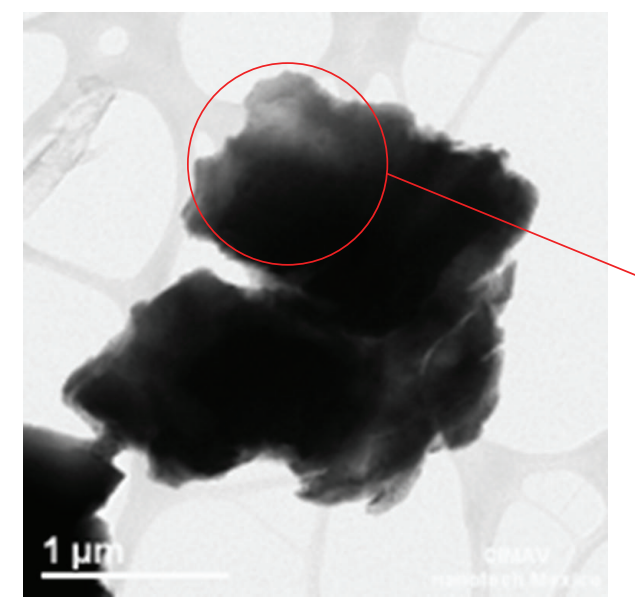

(c)

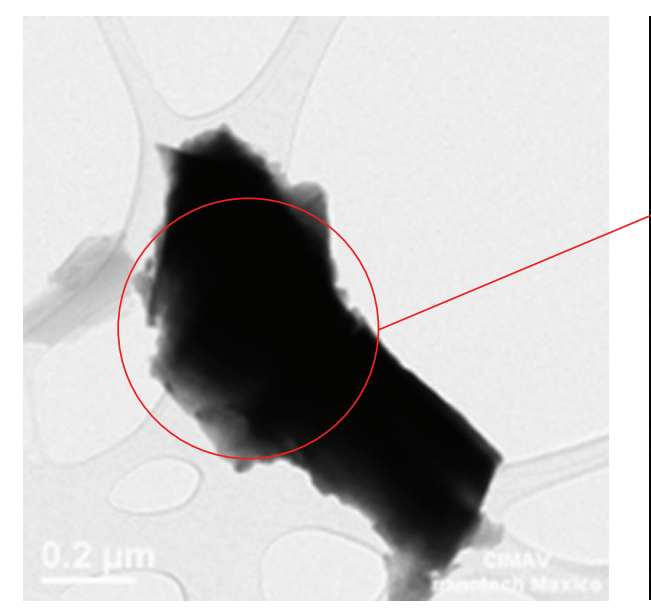

(e)

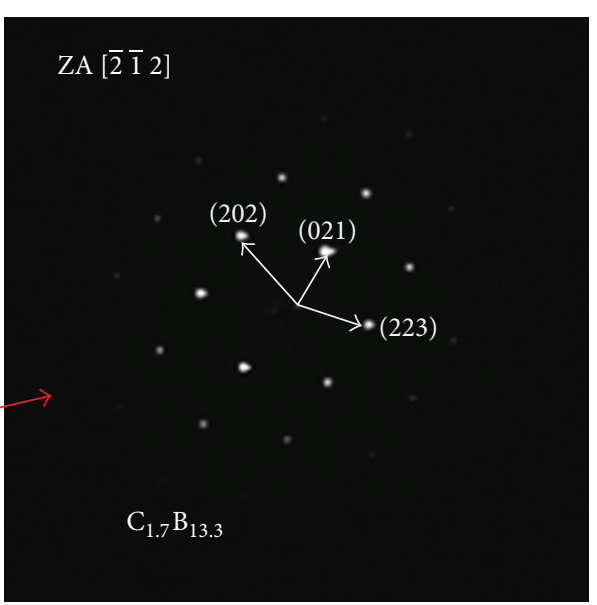

(b)

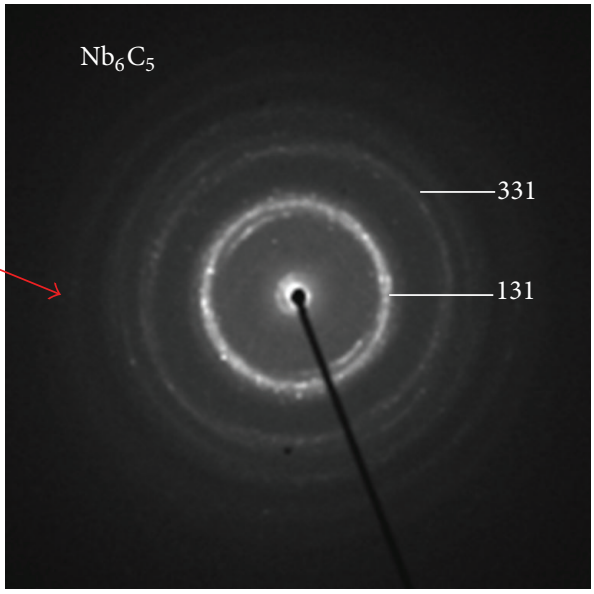

(d)

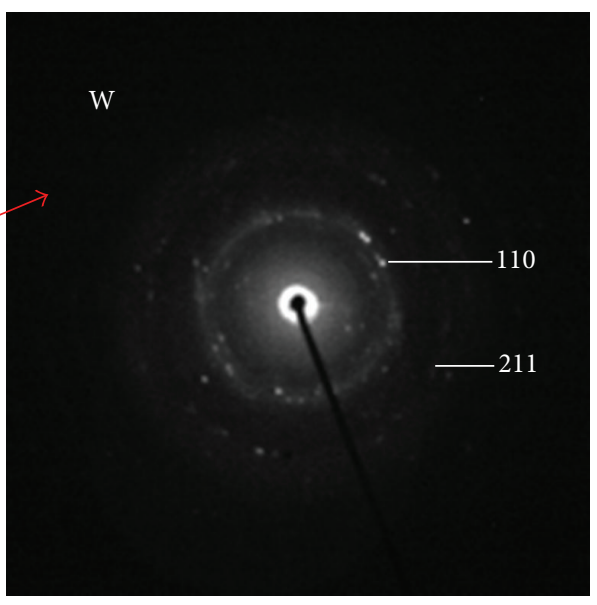

(f)

FigurE 4: TEM images (a), (c), and (e) from powder particles and SAED patterns (b), (d), and (f) from the region delimited by the red circle. (b) Boron carbide phase $\mathrm{C}_{1.7} \mathrm{~B}_{13.3}$, (d) the strongest diffraction rings correspond to $\{131\}$ and $\{331\}$ attributed to $\mathrm{Nb}_{6} \mathrm{C}_{5}$, (f) the diffraction rings correspond to $\mathrm{W}\{110\}$ and $\{211\}$. 


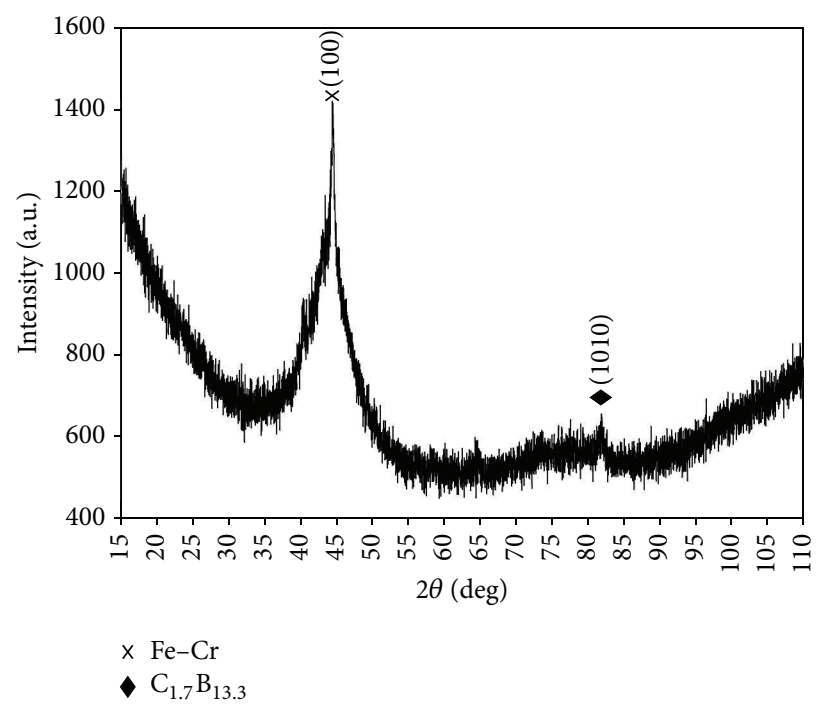

FIGURE 5: XRD pattern of arc spray coating.

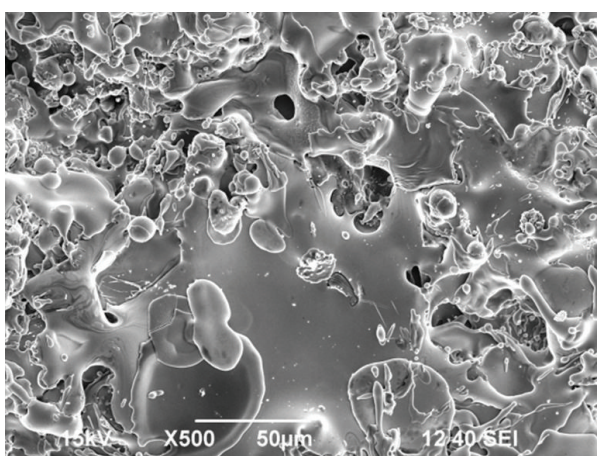

(a)

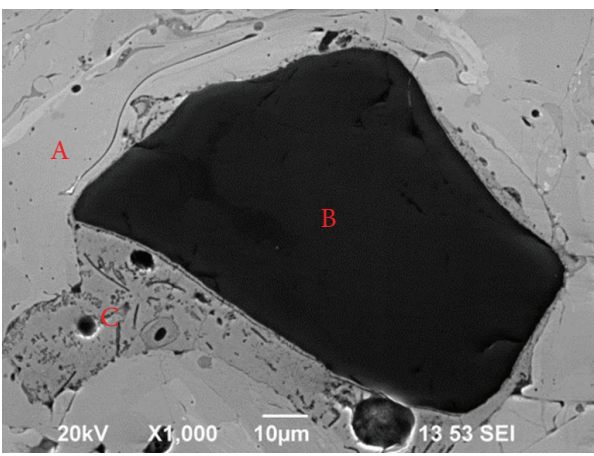

(c)

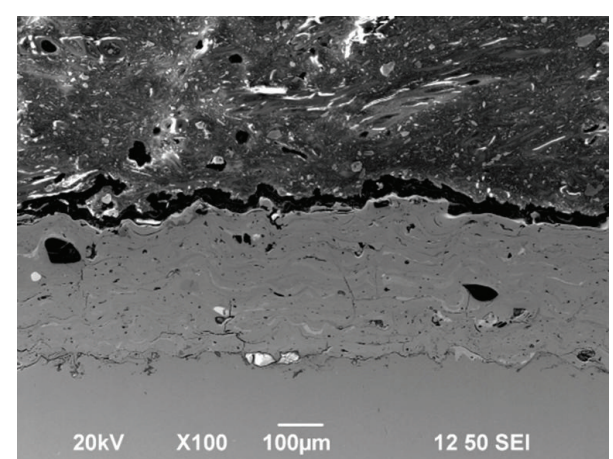

(b)

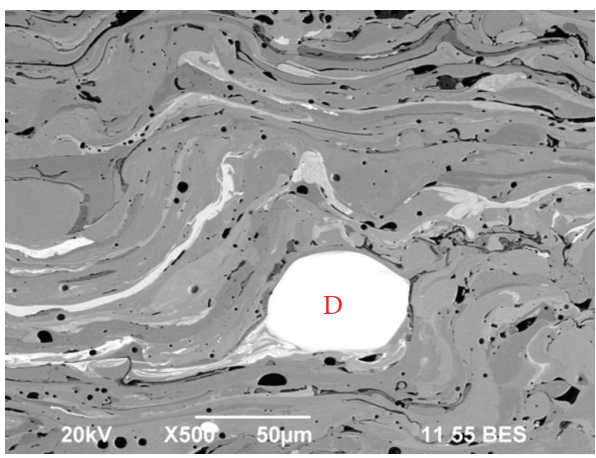

(d)

Figure 6: SEM Images. (a) Surface morphology. (b) Coating cross-section. (c) Magnified dark precipitate and (d) magnified white precipitate in (b).

diffracting rings corresponding to a short ordered material, that is, an amorphous structure.

Figure 8 shows an EDS mapping on the precipitate in the interface boron carbide/matrix. As it can be seen, Fe is observed mainly in the matrix, except in the regions where $\mathrm{C}$ was found. Cr was found well dispersed in the matrix and alloyed with Fe. W was also found well dispersed within the matrix and not forming precipitates. $\mathrm{Nb}$ appeared in regions rich in Cr. Oxygen was found dispersed in Fe zones. Carbon was found in the dark regions, where no other elements were detected. Boron detection lies in the detection limits of the EDSX technique. Because of this, it is possible that boron was not detected during the mapping.

TEM and XRD analysis revealed that the microstructure of the coating was composed of an iron rich phase partially amorphous with elements found in the precursor powder. 


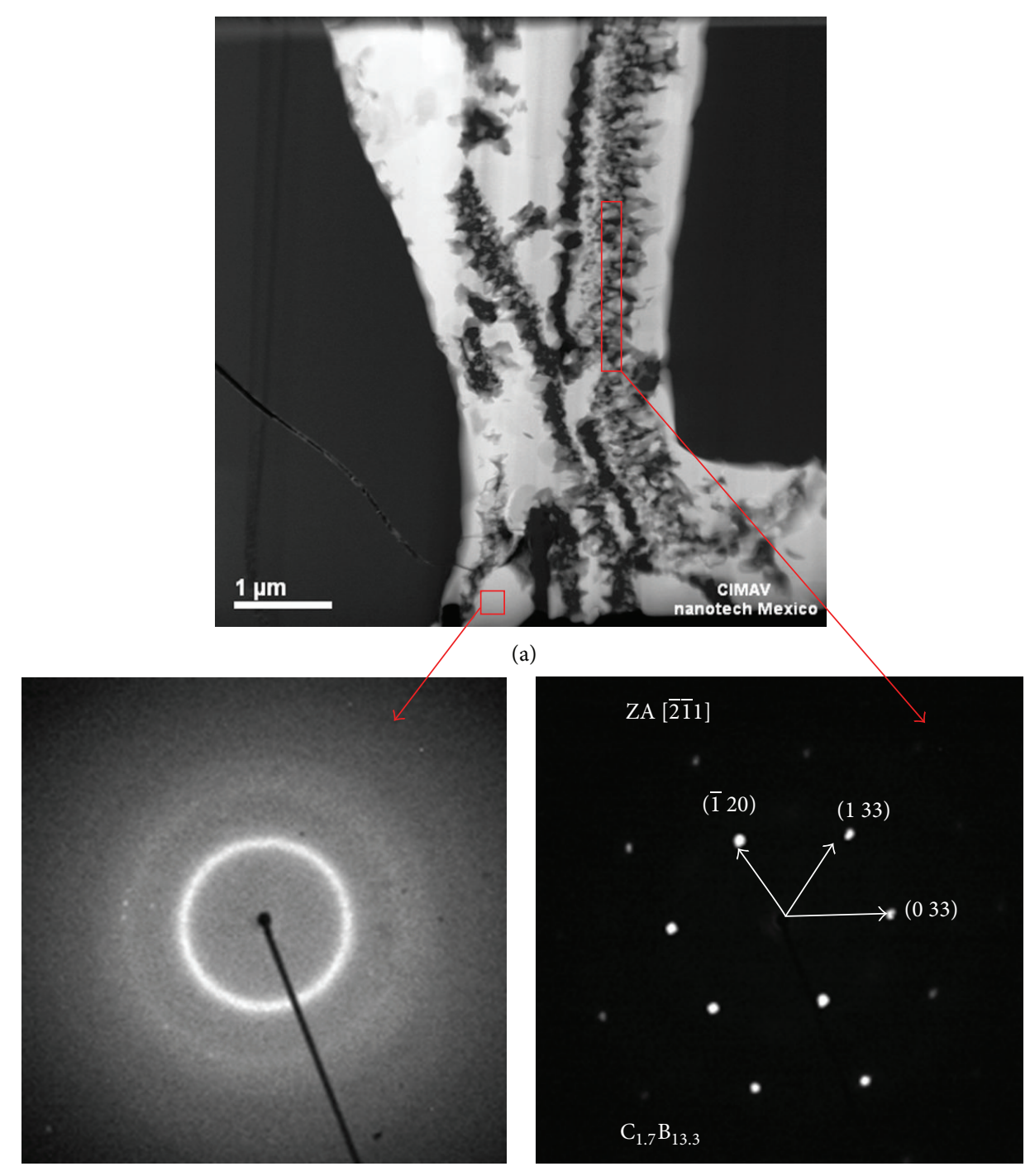

(b)

(c)

FIgURE 7: (a) STEM Z-contrast image showing the interface CB-matrix. (b) SAED pattern from matrix and (c) SAED pattern of the CB precipitate.

Boron and tungsten carbide were found heterogeneously distributed in the matrix and boron carbides presented at the amorphous-crystalline interface. Based on these results it is inferred that the amorphous phase was obtained as a result of high cooling rates and good deformation degree of particles during impact on the substrate. The temperature and velocity average of particles in flight during arc wire spraying have been reported, to reach temperatures of $2200^{\circ} \mathrm{C}$ and $138 \mathrm{~m} / \mathrm{s}$, respectively [28]. Thus, the boron carbides contained in the coating did not dissolve in the amorphous phase due to the average temperature during thermal spraying which was lower than the melt temperature of boron carbide $\mathrm{B}_{2} \mathrm{C}_{13}\left(2447^{\circ} \mathrm{C}\right)$ [29]. Likewise, the tungsten on the powder precursor did not dissolve during spraying because melting temperature of tungsten is $3400^{\circ} \mathrm{C}$ [30]. The formation of tungsten carbide on the coating can be attributed to reaction of tungsten undissolved with carbon of alloy during spraying process. It has been reported [31] that the segregation of tungsten element on FeNiCrBSiNbW coating can be related with redistribution of elements on different phases or the incomplete mixture of powder during wire arc spraying process.

The boron carbides growth in the crystalline/matrix interface can be attributed to partial crystallization by heterogeneous nucleation. In the present analysis, the presence of boron carbides at the particle-matrix interface reveals that the mechanism of crystallization is similar to the one developed in the matrix. Previous studies have reported that these interfaces were formed through adding reinforcement phase such as $\mathrm{Mo}, \mathrm{Nb}$, and $\mathrm{Ta}$ on Zr-based bulk amorphous alloy (BMG) [32]. So, the advantages of producing in situ composite coating by thermal arc spraying are due to the fact that the contents of amorphous and crystalline phases can be controlled during the process. It is worth nothing that in 


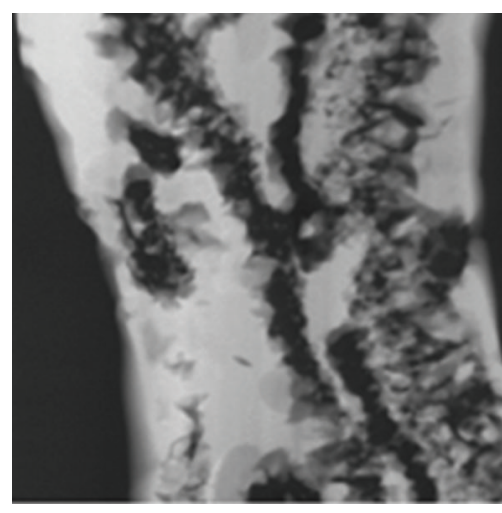

(a)

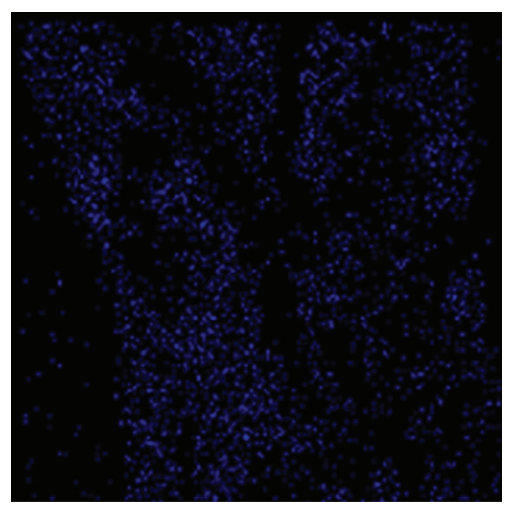

(d)

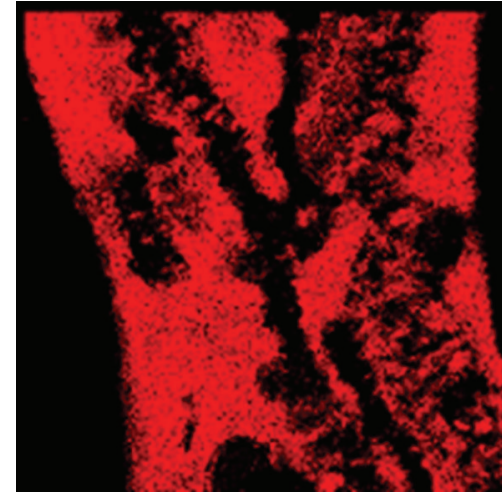

(b)

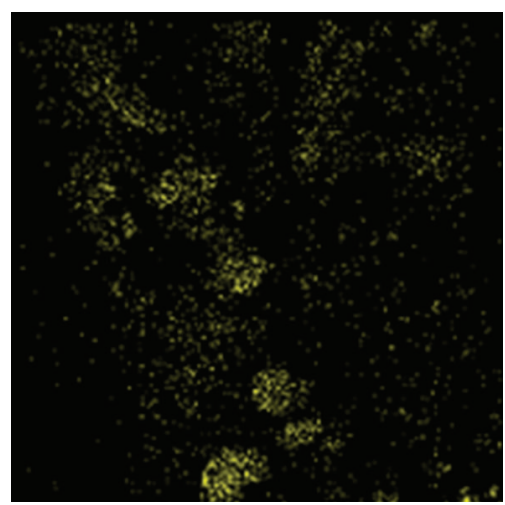

(e)

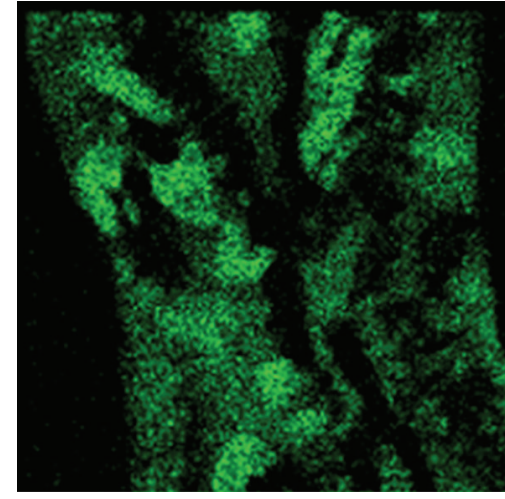

(c)

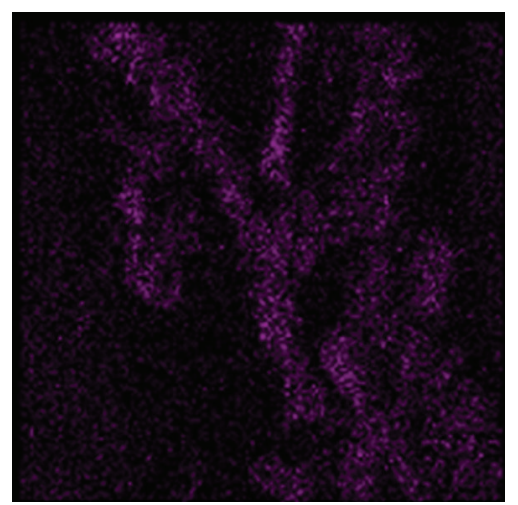

(f)

FIgURE 8: (a) STEM Z-contrast image at the amorphous/crystalline interface. EDSX elemental maps: (b) Fe, (c) Cr, (d) W, (e) Nb, and (f) C.

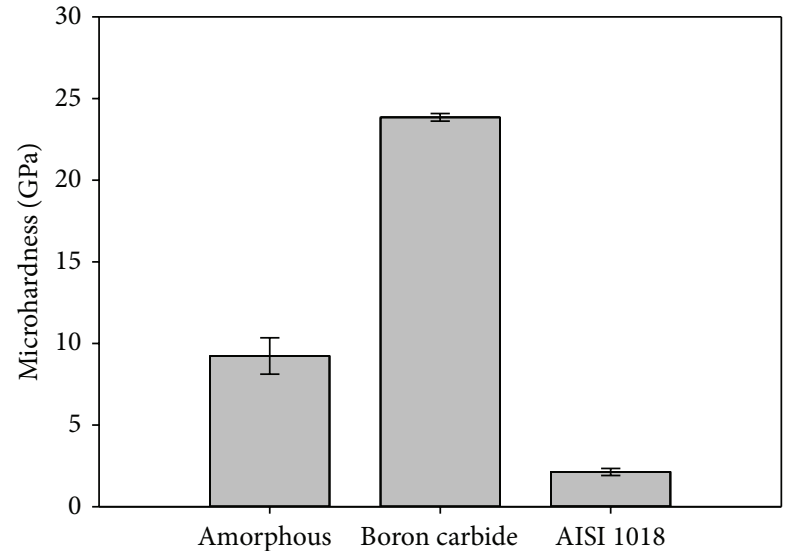

FIGURE 9: Microhardness Vickers of arc spray coating and AISI 1018 steel.

these coatings the interfaces between particles can represent a better mechanical and wear performance due to lower crack propagation through these regions.

3.3. Coating Microhardness. Figure 9 shows the microhardness values that were measured on both coating and substrate. A significant increase of about 4 times can be observed on the as-sprayed coating in comparison with the substrate.
This fact can be attributed to the microstructure which was composed by an amorphous matrix with boron and tungsten carbides heterogeneously distributed. Furthermore, a relative high hardness can be observed on the boron carbide particles. The obtained average value is $23.85 \mathrm{GPa}$ which is more harder than the matrix phase (9.1 GPa).

3.4. Wear Mechanism. Figure 10(a) shows wear rate and volume loss calculated of the coating and the AISI 1018 steel substrate as a function of the applied load. It is noteworthy that at a load of $10 \mathrm{~N}$ the wear rate of AISI 1018 steel is about six times higher than the amorphous/crystalline coating. In this case, the better wear resistance of the coating can be associated with the composite microstructure of coating. Figure 10(b) depicts a magnification of the worn surface on AISI 1018 steel. The worn surface shows few pits, plastic deformation, and parallel grooves indicated by white arrow. The nature grooves were formed by plow out of material. Figure 10(b) shows the worn surface on the AISI 1018 steel labeled with the letter A (Figure 10(b)). Likewise, in the same section (letter: A), the samples were analyzed by EDXS and the chemical nature detected contents of Fe and $\mathrm{O}$. This suggests that the dominant wear mechanism in the substrate is abrasion in combination with plastic deformation and oxidation. The worn coating is shown in Figures 10(c)-10(f). Figure $10(\mathrm{c})$ is a closer view of the worn coating that reveals 

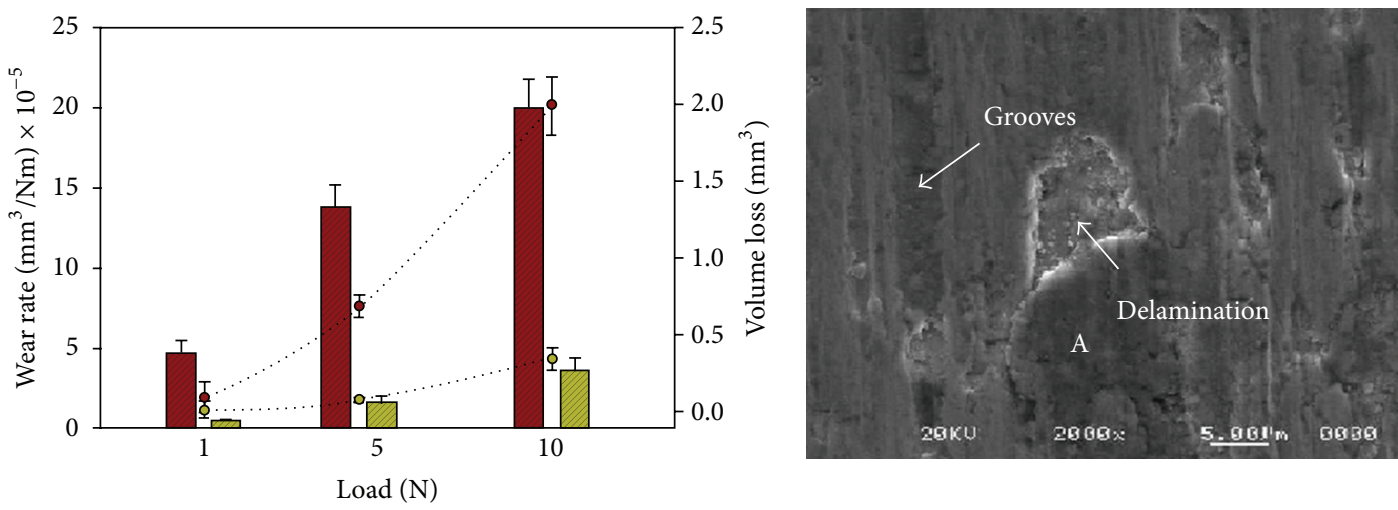

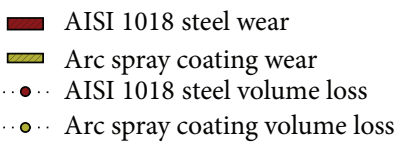

(a)

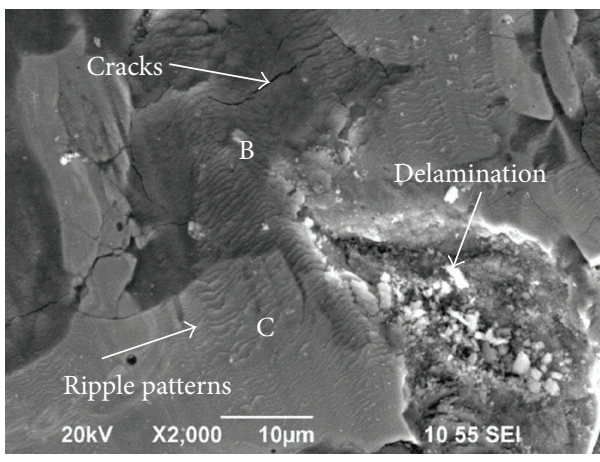

(c)

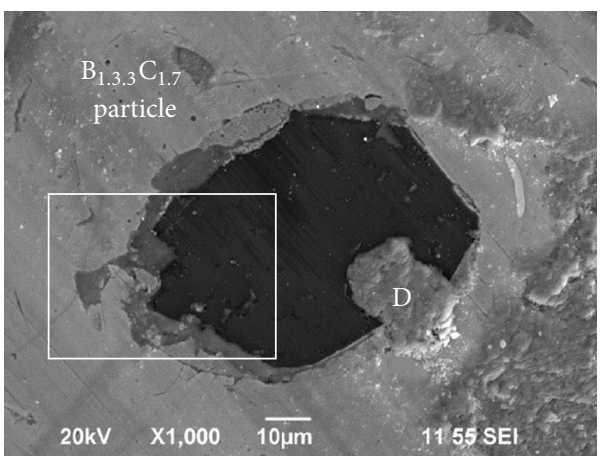

(e)

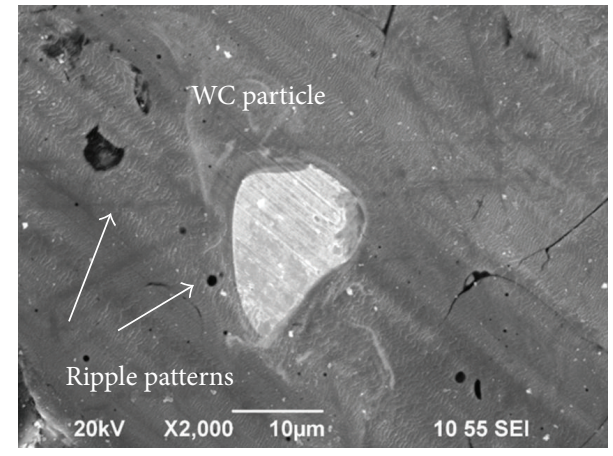

(d)

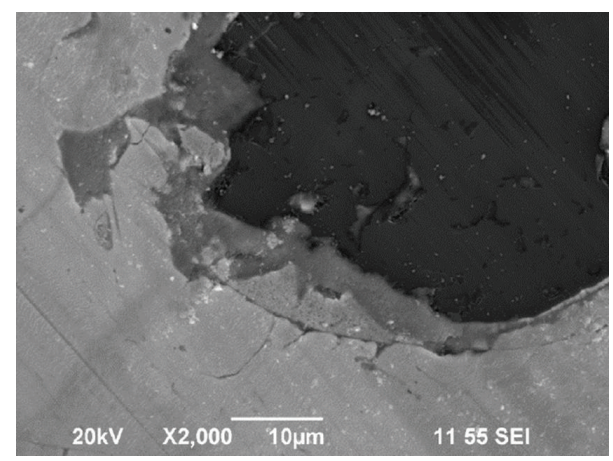

(f)

FIGURE 10: (a) Wear rate and volume loss of the AISI 1018 steel and arc spray coating. SEM images from (b) AISI 1018 steel worn surface with $10 \mathrm{~N}$ of loading, (c) and (d) arc spray coating worn surface with $10 \mathrm{~N}$ of loading.

some pits and a smooth surface that exhibits a ripple patterns indicated by white arrows. In previous studies, Tao et al. [33] observed surface rippling patterns in worn surface of $\mathrm{Zr}$ based bulk metallic glass after wear test which is attributed to rise of temperature on contact surface and this exceeds the melting temperature. They reported that the heat effect results in softening and plastic flow which may appear as rippling pattern. Segu et al. [34] reported melting traces exhibited as ripples-like pattern on the worn surface of Fe based bulk metallic glass during sliding wear at a temperature of $790^{\circ} \mathrm{K}$.
Figures 10(d) and 10(e) show particles of boron and tungsten carbides in the worn surface of the coating. In Figure 10(d) some ripple patterns indicated by white arrows can be seen around of the tungsten carbide. Likewise, at high amplifications can be seen in Figure 10(f), an amorphousboron carbide interface that exhibit around a smooth wear surface, with some ripple patterns but without delamination. In addition, black regions on the worn surface Sections B and D indicated in Figures 10(c)-10(e) were observed which are composed by the elements $\mathrm{O}, \mathrm{Cr}, \mathrm{Fe}, \mathrm{Nb}, \mathrm{Mo}$, and $\mathrm{W}$ 
indicating an oxidation process. The ripple pattern revealed on the coating (Section C) did not show cracks. However cracks were observed only in the oxide region (Section B) depicted in Figure 10(c). Pitchuka et al. [35] reported that relative motion during sliding wear results in friction, which is converted to heat during the process, and the maximum temperature generated is called flash temperature. They observed that the increase in this temperature and the interaction with the surface chemistry of contact area during wear test leads to an oxidation mechanism. Based on the previous results, the delamination in combination with plastic deformation and oxidation can be suggested as a dominant wear mechanism. These results suggests that the composite microstructure increases the wear resistance and decreases the volume loss of arc spray coating due to the increase of its plasticity and the confinement of cracking on the amorphous phase. Previous works have reported the increase of wear resistance after the addition of a reinforcement phase in the amorphous matrix [13-15]. Anyhow, the results found in the present work suggest the improvement in the wear resistance due to the lonely effect of processing.

\section{Conclusions}

The microstructure of coatings consisted of an amorphous matrix rich in $\mathrm{Fe}$ and $\mathrm{Cr}$ with boron and tungsten carbides randomly distributed and boron carbides precipitated at interface boron carbide amorphous matrix. The boron carbide particles act as heterogeneous nucleation sites forming an interface amorphous-crystalline phase around this phase. The increase of hardness and decrease in the wear rate on the coating were attributed to the amorphous crystalline interfaces on boron carbide particles and the boron and tungsten carbides in the amorphous matrix. The increase in the temperature of contact during sliding wear leads to an oxidation mechanism and formation of ripple patterns due to softening and plastic flow in the coating. The wear mechanism of arc spray coating was the delamination in combination with plastic deformation and oxidation. The use of the arc thermal spraying process enables use of a commercial substrate such as AISI 1018 steel for applications requiring high hardness and low wear.

\section{Conflict of Interests}

The authors declare that there is no conflict of interests regarding the publication of this paper.

\section{Acknowledgments}

Araceli Campa-Castilla gratefully acknowledges the financial support from the Consejo Nacional de Ciencia y Tecnología (CONACYT-México) for the doctoral grant. The authors thank the Laboratorio Nacional de Nanotecnología (NANOTECH) in México for the use of HRTEM and Oscar Solís Canto and Miguel Esneider Alcalá for the technical support provided during the preparation of samples.

\section{References}

[1] M. M. Trexler and N. N. Thadhani, "Mechanical properties of bulk metallic glasses," Progress in Materials Science, vol. 55, no. 8, pp. 759-839, 2010.

[2] W. H. Wang, C. Dong, and C. H. Shek, "Bulk metallic glasses," Materials Science and Engineering R: Reports, vol. 44, no. 2-3, pp. 45-90, 2004.

[3] C. A. Schuh, T. C. Hufnagel, and U. Ramamurty, "Mechanical behavior of amorphous alloys," Acta Materialia, vol. 55, no. 12, pp. 4067-4109, 2007.

[4] E. Axinte, "Metallic glasses from "alchemy" to pure science: present and future of design, processing and applications of glassy metals," Materials and Design, vol. 35, pp. 518-556, 2012.

[5] A. L. Greer, "Metallic glasses...on the threshold," Materials Today, vol. 12, no. 1-2, pp. 14-22, 2009.

[6] F. Abdeljawad, M. Fontus, and M. Haataja, "Ductility of bulk metallic glass composites: microstructural effects," Applied Physics Letters, vol. 98, no. 3, Article ID 031909, 2011.

[7] M. S. Bakare, K. T. Voisey, K. Chokethawai, and D. G. McCartney, "Corrosion behaviour of crystalline and amorphous forms of the glass forming alloy $\mathrm{Fe}_{43} \mathrm{Cr}_{16} \mathrm{Mo}_{16} \mathrm{C}_{15} \mathrm{~B}_{10}$," Journal of Alloys and Compounds, vol. 527, pp. 210-218, 2012.

[8] G. Bolelli, B. Bonferroni, J. Laurila et al., "Micromechanical properties and sliding wear behaviour of HVOF-sprayed Febased alloy coatings," Wear, vol. 276-277, pp. 29-47, 2012.

[9] Y. Wu, P. Lin, G. Xie, J. Hu, and M. Cao, "Formation of amorphous and nanocrystalline phases in high velocity oxy-fuel thermally sprayed a Fe-Cr-Si-B-Mn alloy," Materials Science and Engineering A, vol. 430, no. 1-2, pp. 34-39, 2006.

[10] R. Q. Guo, C. Zhang, Y. Yang, Y. Peng, and L. Liu, "Corrosion and wear resistance of a Fe-based amorphous coating in underground environment," Intermetallics, vol. 30, pp. 94-99, 2012.

[11] J. B. Cheng, X. B. Liang, Z. H. Wang, and B. S. Xu, "Dry sliding friction and wear properties of metallic glass coating and martensite stainless coating," Tribology International, vol. 60, pp. 140-146, 2013.

[12] D. J. Branagan, M. Breitsameter, B. E. Meacham, and V. Belashchenko, "High-performance nanoscale composite coatings for boiler applications," Journal of Thermal Spray Technology, vol. 14, no. 2, pp. 196-204, 2005.

[13] S. Yoon, J. Kim, B. D. Kim, and C. Lee, "Tribological behavior of $\mathrm{B}_{4} \mathrm{C}$ reinforced Fe-base bulk metallic glass composite coating," Surface and Coatings Technology, vol. 205, no. 7, pp. 1962-1968, 2010.

[14] T. Terajima, F. Takeuchi, K. Nakata, S. Adachi, K. Nakashima, and T. Igarashi, "Composite coating containing WC/12Co cermet and Fe-based metallic glass deposited by high-velocity oxygen fuel spraying," Journal of Alloys and Compounds, vol. 504, no. 1, pp. S288-S291, 2010.

[15] S. Yugeswaran, A. Kobayashi, K. Suresh, and B. Subramanian, "Characterization of gas tunnel type plasma sprayed TiN reinforced Fe-based metallic glass coatings," Journal of Alloys and Compounds, vol. 551, pp. 168-175, 2013.

[16] B. Movahedi, M. H. Enayati, and C. C. Wong, "Structural and thermal behavior of Fe-Cr-Mo-P-B-C-Si amorphous and nanocrystalline HVOF coatings," Journal of Thermal Spray Technology, vol. 19, no. 5, pp. 1093-1099, 2010. 
[17] J. B. Cheng, X. B. Liang, Z. H. Wang, and B. S. Xu, "Microstructure and mechanical properties of febsinb metallic glass coatings by twin wire arc spraying," Journal of Thermal Spray Technology, vol. 22, no. 4, pp. 471-477, 2013.

[18] J. Cheng, X. Liang, B. Xu, and Y. Wu, "Microstructure and wear behavior of FeBSiNbCr metallic glass coatings," Journal of Materials Science and Technology, vol. 25, no. 5, pp. 687-690, 2009.

[19] J. B. Cheng, Z. H. Wang, and B. S. Xu, "Wear and corrosion behaviors of FeCrBSiNbW amorphous/nanocrystalline coating prepared by arc spraying process," Journal of Thermal Spray Technology, vol. 21, no. 5, pp. 1025-1031, 2012.

[20] J. B. Cheng, X. B. Liang, B. S. Xu, and Y. X. Wu, "Characterization of mechanical properties of FeCrBSiMnNbY metallic glass coatings," Journal of Materials Science, vol. 44, no. 13, pp. 33563363, 2009.

[21] J.-B. Cheng, X.-B. Liang, B.-S. Xu, and Y.-X. Wu, "Formation and properties of Fe-based amorphous/nanocrystalline alloy coating prepared by wire arc spraying process," Journal of NonCrystalline Solids, vol. 355, no. 34-36, pp. 1673-1678, 2009.

[22] J. Zhou, J. K. Walleser, B. E. Meacham, and D. J. Branagan, "Novel in situ transformable coating for elevated-temperature applications," Journal of Thermal Spray Technology, vol. 19, no. 5, pp. 950-957, 2010.

[23] B.-Y. Fu, D.-Y. He, and L.-D. Zhao, "Effect of heat treatment on the microstructure and mechanical properties of Fe-based amorphous coatings," Journal of Alloys and Compounds, vol. 480, no. 2, pp. 422-427, 2009.

[24] X. Wang, J. Heberlein, E. Pfender, and W. Gerberich, "Effect of nozzle configuration, gas pressure, and gas type on coating properties in wire arc spray," Journal of Thermal Spray Technology, vol. 8, no. 4, pp. 565-575, 1999.

[25] American Society for Testing and Materials (ASTM), "Standard test method for wear testing with a pin-on-disk apparatus," ASTM G-99-05, American Society for Testing and Materials (ASTM), West Conshohocken, Pa, USA, 2005.

[26] D. Zois, A. Lekatou, M. Vardavoulias, T. Vaimakis, and A. E. Karantzalis, "Partially amorphous stainless steel coatings: microstructure, annealing behavior and statistical optimization of spray parameters," Surface and Coatings Technology, vol. 206, no. 6, pp. 1469-1483, 2011.

[27] K. Chokethawai, D. G. McCartney, and P. H. Shipway, "Microstructure evolution and thermal stability of an Fe-based amorphous alloy powder and thermally sprayed coatings," Journal of Alloys and Compounds, vol. 480, no. 2, pp. 351-359, 2009.

[28] I. Gedzevicius and A. V. Valiulis, "Analysis of wire arc spraying process variables on coatings properties," Journal of Materials Processing Technology, vol. 175, no. 1-3, pp. 206-211, 2006.

[29] Z. Zachariev, "New superhard ternary borides in composite materials," in Metal, Ceramic and Polymeric Composites for Various Uses, J. Cuppoletti, Ed., pp. 61-78, InTech, Rijeka, Croatia, 2011.

[30] V. Pokhmurskii, M. Student, V. Gvozdeckii et al., "Arc-sprayed iron-based coatings for erosion-corrosion protection of boiler tubes at elevated temperatures," Journal of Thermal Spray Technology, vol. 22, no. 5, pp. 808-819, 2013.

[31] J. Lin, Z. Wang, P. Lin, J. Cheng, J. Zhang, and X. Zhang, "Microstructure and corrosion resistance of Fe-based coatings prepared by twin wires arc spraying process," Journal of Thermal Spray Technology, vol. 23, no. 3, pp. 333-339, 2014.
[32] H. Choi-Yim, R. D. Conner, F. Szuecs, and W. L. Johnson, "Processing, microstructure and properties of ductile metal particulate reinforced $\mathrm{Zr}_{57} \mathrm{Nb}_{5} \mathrm{Al} 10 \mathrm{Cu}_{15.4} \mathrm{Ni}_{12.6}$ bulk metallic glass composites," Acta Materialia, vol. 50, no. 10, pp. 2737-2745, 2002.

[33] P. J. Tao, Y. Z. Yang, and Q. Ru, "Effect of rotational sliding velocity on surface friction and wear behavior in $\mathrm{Zr}$-based bulk metallic glass," Journal of Alloys and Compounds, vol. 492, no. 1-2, pp. L36-L39, 2010.

[34] D. Z. Segu, J.-H. Choi, and S.-S. Kim, "Sliding wear behavior of Fe-based bulk metallic glass at high temperature," Journal of Mechanical Science and Technology, vol. 26, no. 11, pp. 35653570, 2012.

[35] S. B. Pitchuka, B. Boesl, C. Zhang et al., "Dry sliding wear behavior of cold sprayed aluminum amorphous/nanocrystalline alloy coatings," Surface and Coatings Technology, vol. 238, pp. 118-125, 2014. 

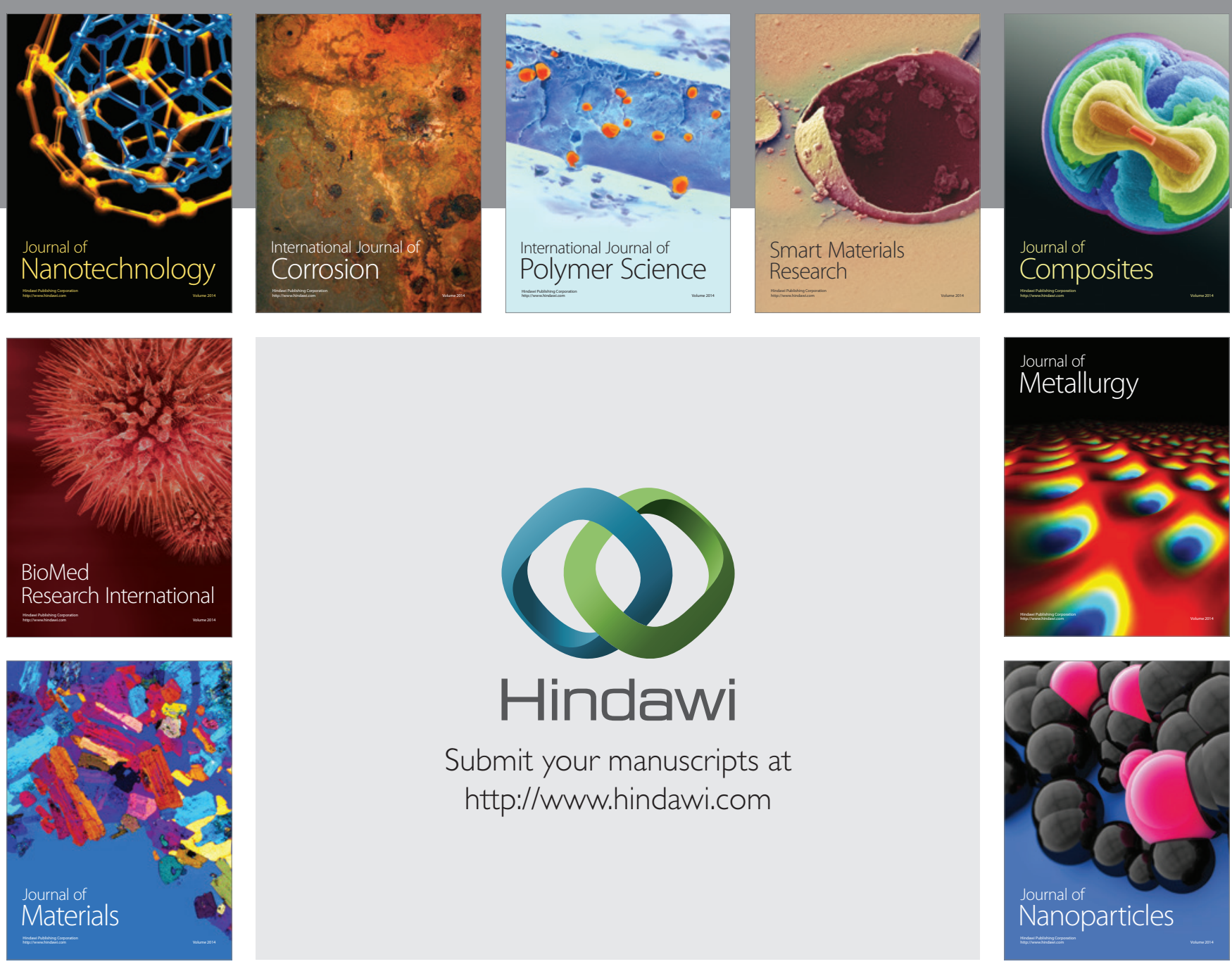

Submit your manuscripts at http://www.hindawi.com
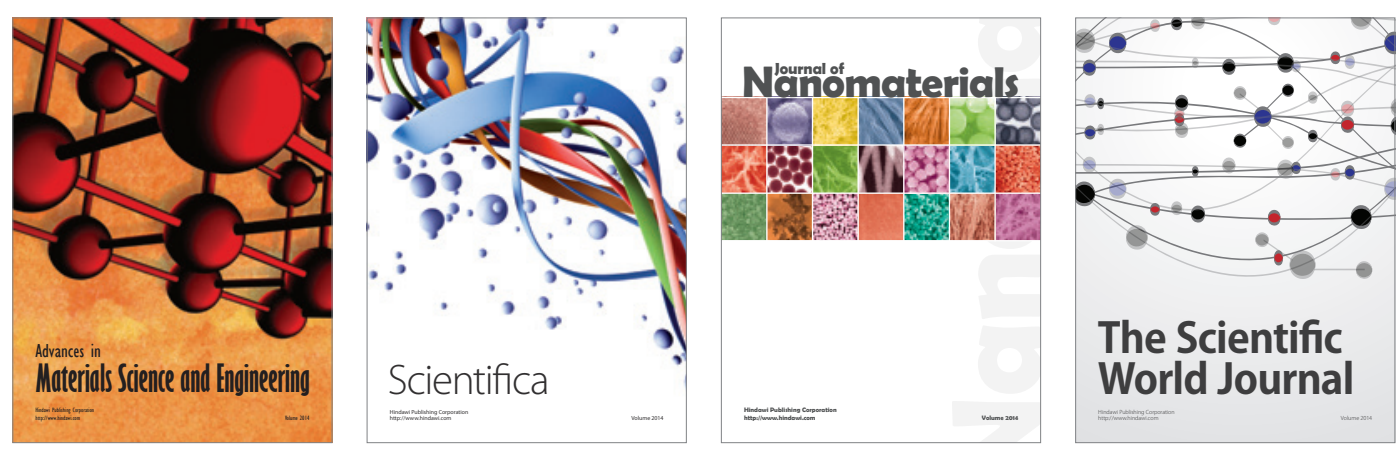

\section{The Scientific World Journal}
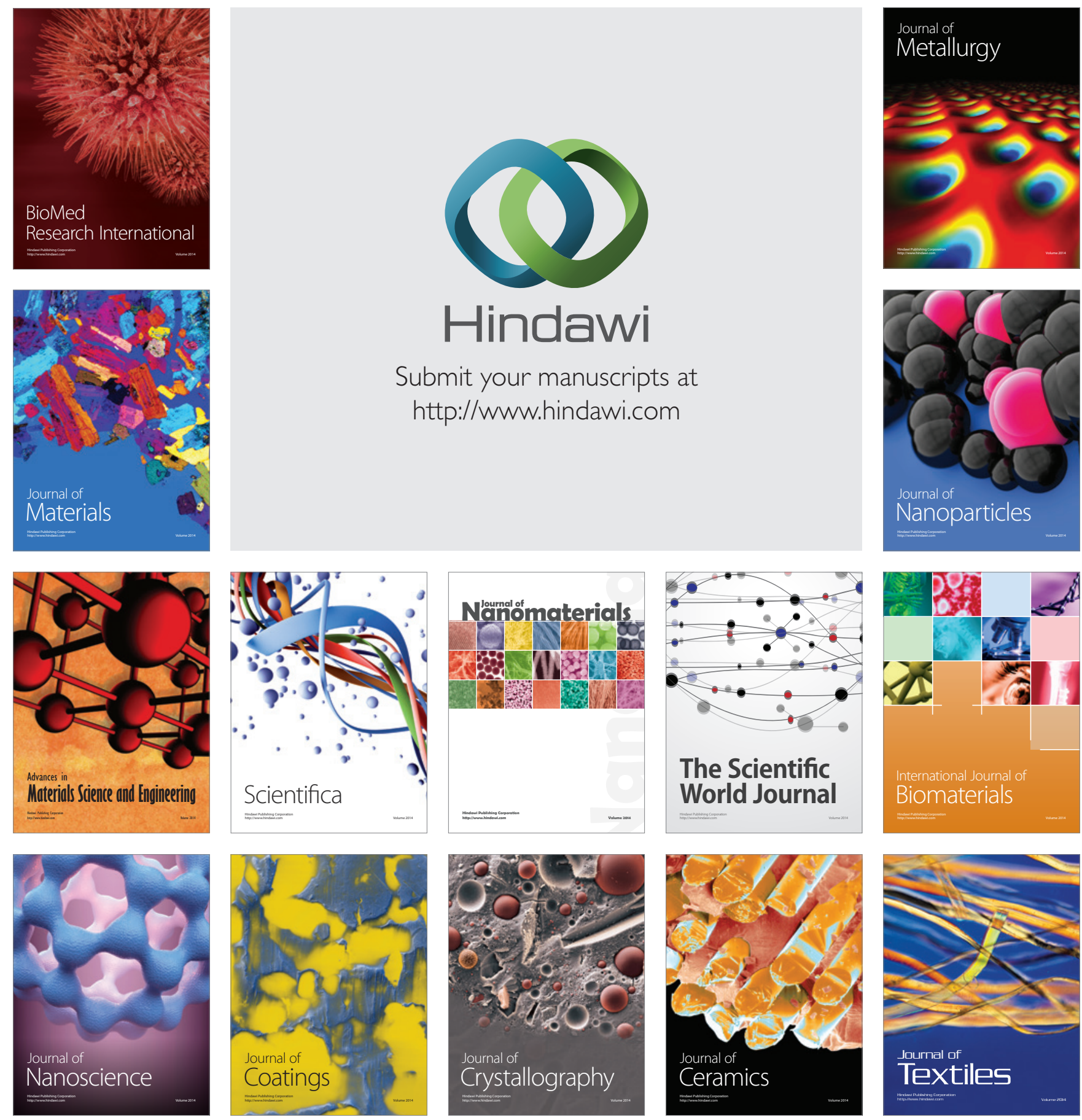